\title{
The Role of Media in Consumption under "Attention Economies": A Study Based on the Interviews of Chinese Postgraduates towards the M\&M's Advertisements
}

\author{
Yuting Xie ${ }^{1}$, Megat Al Imran Bin Yasin², Syed Agil Alsagoff3, Lay Hoon Ang ${ }^{4}$ \\ ${ }^{1}$ Department of Communication, Faculty of Modern Languages and Communication, \\ Universiti Putra Malaysia. Email: shirley_xieyt@hotmail.com \\ ${ }^{2}$ Department of Communication, Faculty of Modern Languages and Communication, \\ Universiti Putra Malaysia. Email:megat@upm.edu.my \\ 3 Department of Communication, Faculty of Modern Languages and Communication, \\ Universiti Putra Malaysia. Email: s_agil@upm.edu.my \\ ${ }^{4}$ Department of Foreign Languages, Faculty of Modern Languages and Communication, \\ Universiti Putra Malaysia. Email: hlang@upm.edu.my
}

\begin{abstract}
The rapid development of media in the world promote the prosperity of the economy to a certain degree. Advertisement, as one of communication form of mass media, gradually becoming one of an important part in the attention economy. In view of these, the research chooses M\&M's advertisements as examples to discover what factors attract audiences' attention and then lead to consumption, and how they play their role during the process. Three methods are employed in this research: in-depth interview, observation and textual analysis. Five Chinese postgraduate students are selected as objects, and they answer the questions by the researcher after they watched two types of M\&M's advertisements (celebrity-based advertisement and content-based advertisement). Through the combination of interview, it can be found that both celebrities, memory and social media platform can exert their role in the attention economy. This article also expects to offer a reference for advertisers and product manufacturers, helping them adjust their marketing strategies rationally by using celebrities and other elements.
\end{abstract}

Keywords: Attention Economy, Advertisement, Media, Celebrities, Memory.

\section{Introduction}

Nowadays, people are currently living under an era of "Attention Economy". A large number of scholars have been discussing the value of audience attention and commercialization under the new media environment for a long time, and most of them believe that attention is one of the most valuable resources in contemporary capitalism (Zulli, 2018). Thus, people's attention has already become a valuable and tradable commodity in the current fast-flowing society (Law, 2011). Many scholars are aware of the impact of the contemporary attention economy on the Internet (GarcíaRapp, 2017). Under the context of the information era, this project aims to focus on the role of media in the attention economies.

\footnotetext{
(c) AesthetixMS 2020. This Open Access article is published under a Creative Commons Attribution Non-Commercial 4.0 International License (http://creativecommons.org/licenses/by-nc/4.o/), which permits non-commercial re-use, distribution, and reproduction in any medium, provided the original work is properly cited. For citation use the DOI. For commercial re-use, please contact editor@rupkatha.com.
} 
As an essential part of the media, advertisement plays a critical role in raising people's attention. This article mainly discusses how advertisements use celebrities, memory and social media to attract people's attention and turn their attention to consumption behaviour. In order to obtain more accurate results, two different types of M\&M's advertisements will be selected for further interview. In order to discover audience response regarding different factors, this study selected a celebrity-based advertisement and a content-based advertisement from the same brand to test. Both of them are typical and as varieties, they are considered their consistency by this research (such as the period of broadcasting time, the quality of the screen, the language of the subtitle and so on). In addition, observation and textual analysis will be combined to carefully explore the interviewees' thoughts and to discover further details.

Generally, this article will concentrate on previous literature and research methods, then constitute and carefully explain the framework for the role of advertisements in the attention economy. Furthermore, it will display the analysis of the five interviewees respectively. Finally, this study will compare predictive analysis with actual analysis, as well as propose shortcomings and future research directions.

\section{Literature Review}

Attention is placing audiences' mental activities on specific information items. In other words, these specific items come into people's consciousness and draw their attention, and then lead people to decide whether to take action. The economic model formed by this attention is called the "attention economy" (Lanham, 2006). Specifically, the attention economy refers to an economic model that attracts the attention of users or consumers to the maximum, and cultivates potential consumer groups in order to obtain the greatest future business benefits (Goldhaber, 1997). In this fiscal status, the most important resource is neither the traditional monetary capital nor the information itself, instead, the audiences' attention. When they pay attention to a certain product, they tend to become a consumer easily.

In the information era, attention as a sort of resource that can convert to business value and economic benefits. Accordingly, the industries that operate attention resources such as media and advertising gradually emerging. Media, as the concentrator of attention value, has played an indispensable role in the attention economy. In the advertisement, one of the important means that can grasp the attention of the public is through visual and emotion, such as attractive celebrity or content. This is why the attention economy is also called the "eyeball economy" (Jiao, 2018). In China, some scholars tend to realize the mutual conversion of the attention economy from eyeball to minds through the value interaction between enterprises and customers (Hu, 2003; Jiang, 2005).

As for research, the conceptual framework is necessary for thorough understanding. Figure 1 describes the framework for the role of media--especially advertising and social media in attention economy. The advertising can be divided into two types, stars constitute the celebrity-based advertisement and memory points form content-based advertisement. Together with social media platforms, the celebrity and memory help advertisements catch the audience's attention and impact on economies. Besides, it depicts the interplay of celebrities, social media and memory through advertisements. 
3 The Role of Media in Consumption under "Attention Economies": A Study Based on the Interviews of Chinese Postgraduates towards the M\&M's Advertisements

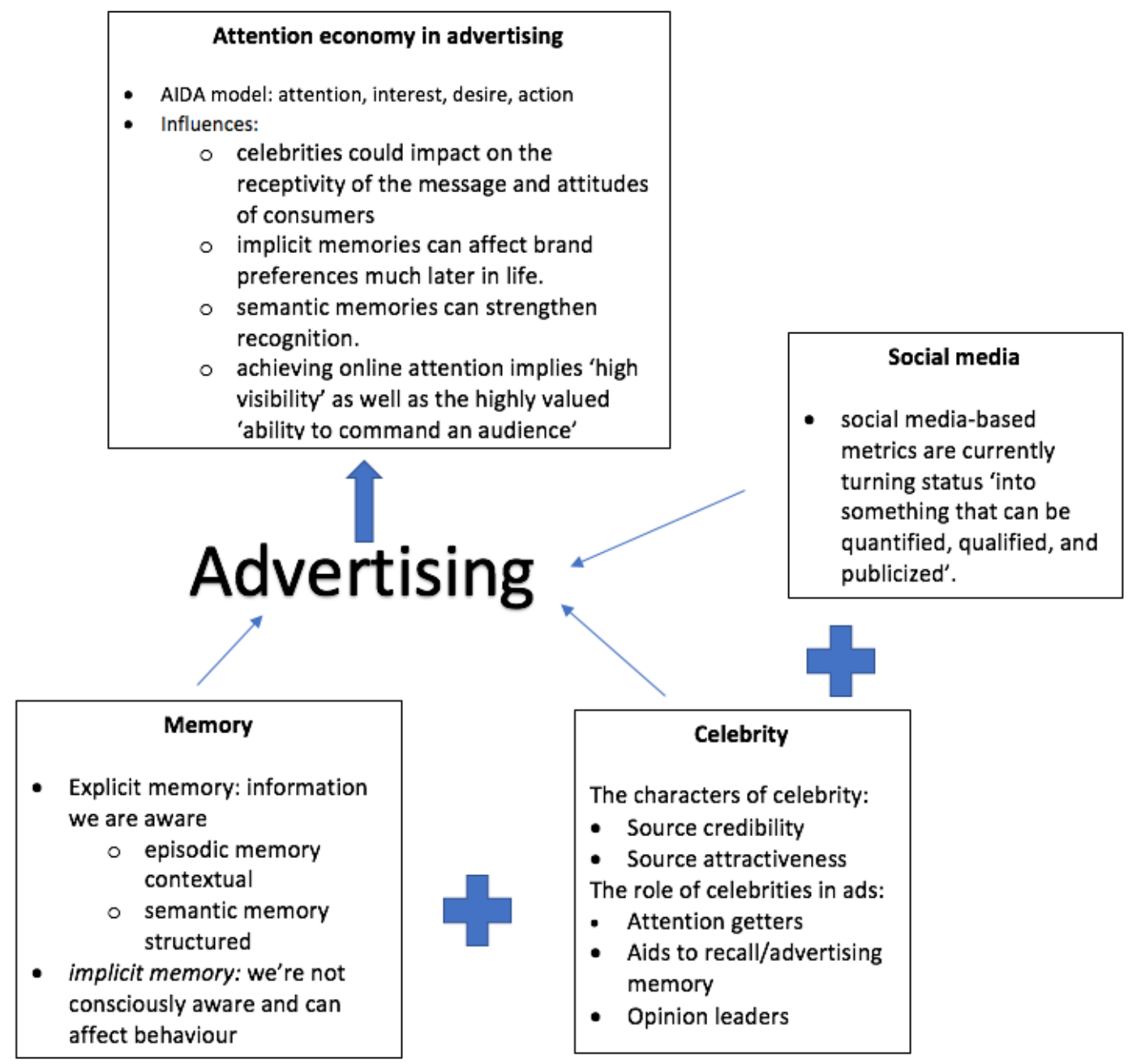

Figure 1: Conceptual framework

Traditional media followed a model called AIDA--Attention, Interest, Desire and Action (Ratcliffe, 2014), which put attention as a major and the first stage of attracting potential consumers. For present advertisers, they still can affect consumer behaviour by raising the audience's attention.

Then three major influencing factors come out--memory, celebrity and social media, all fo which play significant role in raising the attention and stimulating consumer behaviour when the audience watch the advertisement. There are two types of memory which are helpful to consumer behaviour. The first type is the semantic memory, which means a more structured record of facts, meanings, concepts and knowledge that come from contextual memory (such as advertising slogan or advertising lines). Another type is implicit memory, which is based on certain brand preference of the audience. Such sort of preference is produced by unconscious associations with the previous memory and it may influence the audience future life or choice (Brandt, 2017). Then, the second factor, celebrity. It is believed to catch the audience's attention, make the ad memorable and acceptable and desirable based on its credibility and attractiveness (Spielman, 1981). In addition, celebrity can deliver their image value to advertisements and products (O'Mahony \& Meenaghan, 1998). So, the celebrity could impact on the receptivity of the message and attitudes toward the brand or product. In this way, the possibility of consumer behaviour becomes larger. The last factor, 
social media. It can help to achieve online attention by 'high visibility' (Marwick, 2013), which contribute to advertisements more and more with each click and view. For instance, on Wechat (a typical Chinese social media application), the attention is raised by taking the form of views, comments, and subscriptions.

It's worth noting that not only do memory, celebrity and social media raise attention respectively, but importantly, they collectively combine to make a difference. Nowadays, using popular idols to endorse brand and products is very popular due to the synergistic effect of celebrity and memory. These popular idols can act as aids to recall the audiences' memory of the advertisements (Friedman, et al., 1979) and vivid advertising memory is a key to convert the nonconsumer to the real consumer. Moreover, the celebrity also uses social media to influence and persuade the audience (including their fans) to consume. The "ability to command an audience" of social media (Marwick, 2013) and the attractiveness of celebrity contribute together to form memory and create an online persona, or self-brand (García-Rapp, 2017). To a certain degree, celebrities can be recognized as opinion leaders or reference group effectively with the help of social media.

\section{Methods}

After conducting an extensive conceptual framework on the role of media in attention economies, this study carried out a small-scale interview. Combined with the method of observation and textual analysis, interviewers use a one-on-one conversation with interviewees in the form of face-to-face to observe their reactions and responses.

\section{Sample}

There are five Chinese people as interviewees, including two boys and three girls. The statistic characteristics of participants in the study were as follows:

-Age: $20-26$ years

-Occupation: Students

-Had/Hadn't the experience of chasing celebrities.

-Using social media in daily lives.

\section{Methods and procedure}

The interviewers found participants through personal contact. To respect every participant, interviewers gave them a choice whether to join in or not, as well as ensure confidentiality of their information. The interview of each person was half an hour long. These interviewees were required to answer the questions along the following lines:

-Celebrity affection

How advertisements catch audiences' attention by using celebrities in the context of China?

-Advertising and social platform 
5 The Role of Media in Consumption under "Attention Economies": A Study Based on the Interviews of Chinese Postgraduates towards the M\&M's Advertisements

What kind of role do advertisements play in raising the attention of their audiences and promoting consumer behaviour?

Many detailed questions about the topic are extended and were utilized by specific investigation of research. The process of discussion was audiotaped and translated, and then the statistics were analyzed based on the arranged study outline.

This study analyzed the first question through interviewees' attitudes about their idols, which associated with their consumption. For example, some questions like will you have the desire to buy something which is not useful but only endorsed by your idol? After that, they will watch two advertisements in the same brand (M\&M's), one of which is endorsed by a famous Chinese singer Eason Chan (Figure 2) and another focus on its creative content (Figure 3), expecting to discover the attractive elements (celebrities or creative contents) for them. Several questions such as what are the most impressive points of the two advertisements in your mind, whether you will share advertisements you like with others on platforms?

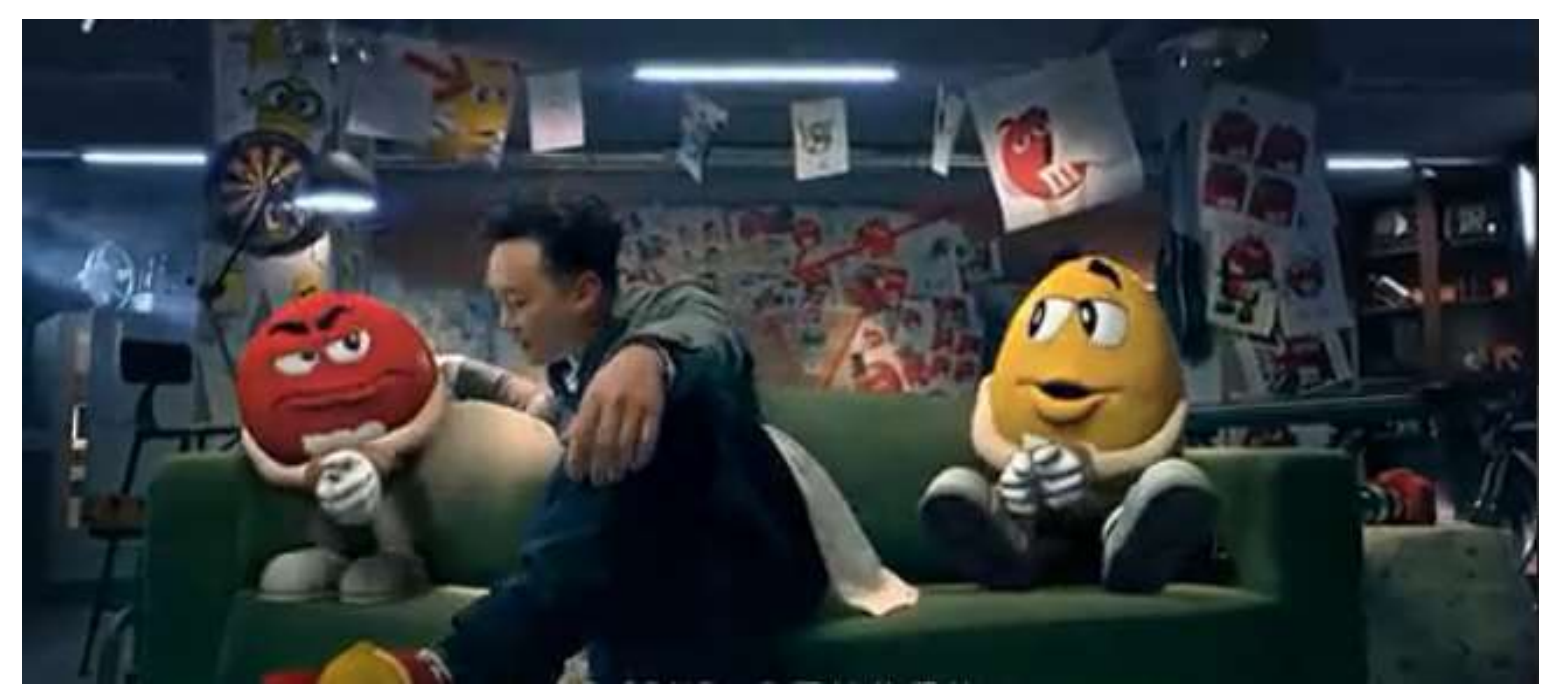

Figure 2: Celebrity-based advertisement of of M\&M's.

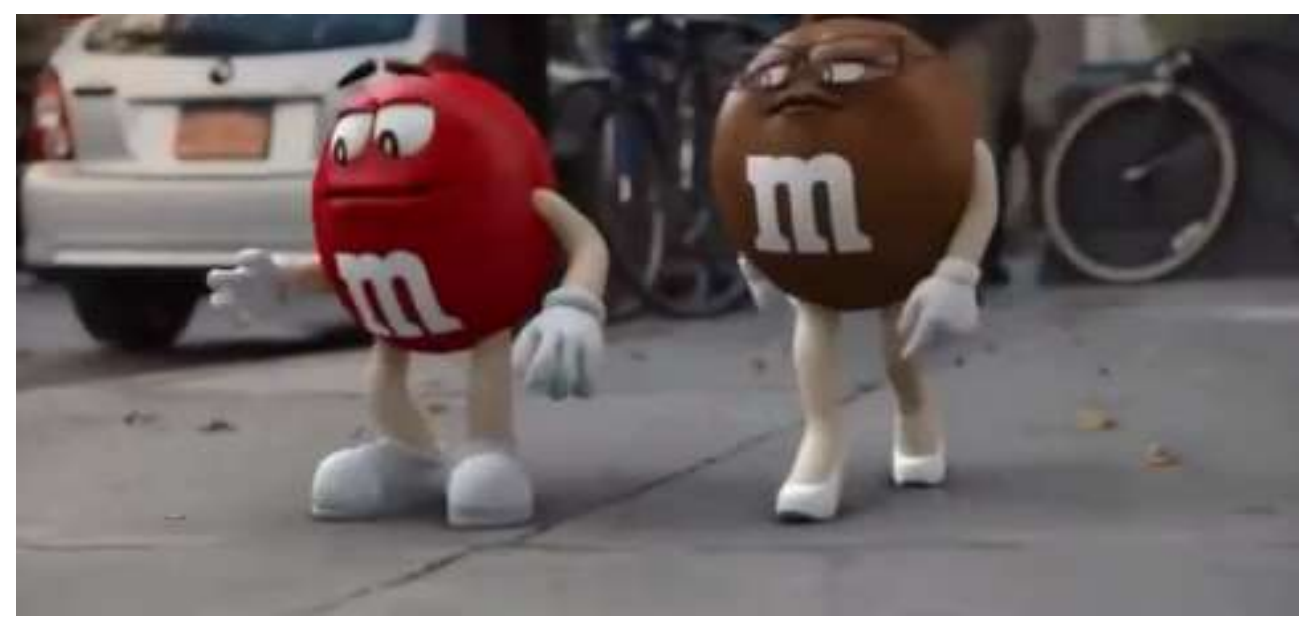


Figure 3: Content-based advertisement of M\&M's.

The method of observation was utilized by this interview, which can be defined as "a unique method for investigating the enormously complex and diverse experiences, thoughts, feelings, and activities of human beings" (Jorgensen, 2015). It refers to the researchers interacts with people when they collect information, which is a direct approach to collecting data and information, best for the study of human behaviour in particular (Singh, 2010). Therefore, this study observes the interviews from the following aspects, covering their physical and mental activities. Generally speaking, the reason of the utilisation of observation is that it is easy for interviewers to read participants' feelings through their eyes, facial expressions, or subtle movements, then make an in-depth analysis of this study. For instance, some of the interviewee's smiles, laughing, gestures' change or direct answer without hesitation, which implies they may be interested in the specific topic or advertisement or affirm their thoughts. Some of them present confused expressions, which indicate they may hold opposite attitudes or difficult to make a decision. Considering this, it not only helps interviewers in understanding their verbal responses more efficiently but also contributes to the comprehending of their micro-expression.

These methods are suitable for interviewers to get into the more in-depth topic and acquire more detailed information because specific problems and abstract factors (such as feelings, attitudes and judgements) can be evaluated through it easily. Meanwhile, they are more controllable and feasible for researchers to practice in this qualitative research.

In addition, the method of textual analysis will be used for further investigation. Some theories (that are mentioned in last past of this article) were applied and illustrated, especially about celebrities, memory, social media platforms, attention economies, etc., for demonstrating how the attention of people transform to action through their recognition as well as the function media play in this process. The advantage of this method is that it lays the foundation for the research as well as form a logical framework. When it comes to the analysis in the subsequent report, it is necessary to offer theory support for the conclusion.

\section{Rationality and evaluation}

In fact, the study concentrates on the interactive effects of these methods, which contains a kind of rationality. Although the research cannot guarantee absolute objectivity (which the researcher always pursuit as well), the subjective truth is also valuable for this study. Besides, with several considerations in minds, this study focuses more on the way they discuss rather than only what they talk. Because it is an interview that interviewees tell not merely about the content itself, but how they say to their opinions and how interviewers feel when they describe their opinions, which is deeply embedded in social research. To some extent, the respective function of these methods together with their interactivities, leading to applicable reasons this study use them, not only adapt to the effective implementation of research but also ensure relative realness.

Referring to the evaluation of methodology, there are some important points need to be considered. Face-to-face interviews are characterized by synchronous communication in time and place, which create an opportunity for the observation. Several social cues (e.g., body language) can be interpreted in this process. However, accordingly, these values from interviewees depend on what they want to present to the interviewees. This situation implies that the participants may answer the information they received in a specific direction, which can be regarded as a kind of 
7 The Role of Media in Consumption under "Attention Economies": A Study Based on the Interviews of Chinese Postgraduates towards the M\&M's Advertisements

disturbing interviewer effect (Opdenakke, 2006). Interviewers' personal guidance exists in this research more or less, however, the researcher tries to avoid it as possible. The investigator attempts to control the self-consciousness of interviewer effect and treat each question objectively.

\section{Results and Discussions}

In this interview, five Chinese college students as respondents, give different physical reactions to advertisements, and each of them has different attitudes about advertising.

$\mathrm{BY} \mathrm{Xu}$ paid attention mostly to advertisements with interesting and creative content. When she has watched the ad of M\&M's with the celebrity (Eason Chan), she was calm, and after watching the one without stars, she laughed out and commented that the dialogue was funny. For JY Li, the second advertisement (exciting and dramatic one) seemed to attract him more, which can be exemplified by his involuntarily laugh and upright postures. Another respondent KW Yu paid almost the same degree of attention to both commercials with smiling during the watch process, and he said that it is difficult to compare which one was more creative. In contrast, TJ Li carefully watched the two advertisements but was not interested in both ads and expressed a puzzled expression when viewing the second advertisement, because she could not understand what it wanted to convey. Finally, she preferred the first advertisement could be more attractive for her because she thought the actor in the second one looks ugly. And JJ Wang did not have apparent facial expressions or other physical reactions when watching commercials, but when asked which the partial advertisement is, he chose the first one without hesitation and thoroughly explained his reasons: this advertisement is easier to understand and the dialogue and celebrities inside left him with a more in-depth impression.

In fact, all interviewees have their unique memory of advertisements after watching the commercials; the celebrities, plots, and actors' lines are the most concerning parts for them. They can all notice and remember the superstar in the ad, and when the advertisement lacks this point, the exciting plot would be the most eye-catching point. Although celebrities are so influential and all respondents also have their favourite stars, this does not mean that stars can significantly influence their consumer behaviour. KW Yu and TJ Li have idols they love, and they claim that they are crazy for their idols, but that doesn't mean that they will buy all the products what their icons endorse. TJ Li inclined to choose the product which her idol has endorsed when comparing the same type of products. She is willing to buy cheap products without hesitation, such as snacks and toothpaste, but she will not buy cars which also endorsed by her idols since she cannot afford it. KW Yu said that he would be sensible when purchasing goods, and he will focus more on the product itself than the spokesperson of the product. For JY Li, JJ Wang and BY Xu, advertisements of celebrity endorsements have less impact on their consumption: they will not buy things they do not need just for their favourite celebrities. Celebrities do encourage them to pay more attention to those products what celebrities endorsed, but when they consider whether to pay for these things, the product itself is the only element of their decision.

In addition, every interviewee agrees that they prefer to view no advertisements on social media, but social media platforms are still playing an important role for the advertiser to gain viewers' attention. ZY Li expressed strong resentment against advertising on social media platforms, like WeChat, Facebook, and Instagram. He believes that he uses such software to communicate with his friends, then, the content in the software is related to his life and belongs to his private space. Therefore, he will directly ignore the advertisements that appear on social software, and it is 
even less likely to share ads with friends. At the same time, he believes that it is reasonable for advertisements to appear in other places, such as video sites; he even read those advertisements carefully and buys their products later. Similarly, TJ Li also does not like advertising on social networking sites. She will deliberately choose to use social software which with less advertisement, and will not look at advertising on the software or share advert with friends unless that advertisement has her idol, and he looks charming in the ad. For KW Yu, he does not like view advertisements on social media, but he will share interesting advertisement matter and open the ad shared by his intimate friends through social media platforms. In contrast, JJ Wang and BY Xu have a more moderate attitude toward advertising. They also directly ignore advertisements on social media, but when the ad is about the products they are interested in, they may be concerned about these advertisements and share them with their friends. BY Xu bought Dior's lipstick for advertising on WeChat and distributed the lipstick advertisement to her female friends, and JJ Wang cannot stop to view every ad about men's shoes.

Results from the five interviewers follow the conceptual framework, as presented earlier. Memory, celebrity and social media have been found having positive impacts on raising participants' attention in advertisements, while their consuming behaviour was not influenced to a large extent by advertisements which have already caught the attention of the participants. Thus, attention as the first stage of AIDA contributes to economies indirectly.

In general, the impact of celebrity endorsement is moderate on raising attention for these five interviewees. Two of them had a deep impression of the first advertisement (celebrity); two of them preferred the second advertisement due to the creative content; another one was impressed by both. For those whose attention has already been raised by ads whether celebrity endorsed or not, these participants were able to recognize the product easily. After a period, they might buy the product if they were interested or saw the product around them when they selected goods, which proves the impact of advertising memory is quite positive on consumer behaviour as long as the price of the product is acceptable. As for social media, it seems workable, even though not a perfect way to raise the attention by advertising on social media platforms because it can easily make two of them annoyed when advertisements showed suddenly in front of them. They felt uncomfortable because they were interrupted by precipitate advertisements. However, for the other three, they only watched ads which presented the brand or the type of products they were interested in. Thus, it will be more effective for advertisers and product manufacturers when their advertisements were put in public according to the user's personal preference of products by tracking the user's searching history online. In addition, consumer behaviour largely depends more on the product itself rather than celebrity endorsement, though celebrity plays a significant role in forming the semantic memory or implicit memory.

Before research, this study initially considered celebrities themselves, as well-known characters, can immediately capture the attention of the public when they appear in advertisements and eventually turned their attention to the ad itself. Because compared to boring advertisements or the sudden emergence of creative advertisements, advertisements containing celebrities already have a specific audience base (i.e., fans of stars). Even so, this study did not believe that celebrity influence on viewers would be the only factor in purchase behaviour. In fact, the interviewees confirmed: even if some of them have the highest level of affection for their favourite idols, their top priority is the practicality of the product itself when purchasing idol endorsements. Nevertheless, contrary to previous predictions, respondents were not satisfied with advertisements appearing on social media. All respondents cared about privacy since they tread their social accounts as a platform for personal information sharing, so some people are repellent to 
9 The Role of Media in Consumption under "Attention Economies": A Study Based on the Interviews of Chinese Postgraduates towards the M\&M's Advertisements

advertisements appearing on social platforms. Therefore, if the brand and product manufacturer wants to attract the audience in social media, they need more advanced advertising skills, such as targeting users for accurate advertising, which can both avert user aversion and improve advertising effectiveness.

\section{Conclusion}

In conclusion, attracting people's attention tends to create business value and gain economic benefits. And memory, celebrities and social media platform all play an essential role in raising people's attention. To be specific, through this research, the celebrity is the primary factor to attract consumer's attention, and advertising memory provides a potential impact on consumer behaviour. Meanwhile, the social media platforms are able to provide high visibility for brands and have the ability to persuade the audience to consume. Therefore, for advertisers, they can attract the audience' attention through the combination of celebrity, creative memories and the social media platform. During the process of conversion from attention to the economy, they can acquire the brand of public awareness and gain economic benefits.

In the previous phase of the study, the researcher did the interview and detailed analysis. However, there are still some points that need to be improved. The research did focus on how advertisers grasp consumers' attention rather than how they keep consumers' attention. People's attention is limited and easily transferred, especially in the context of this information era. Attention selection is also very necessary since the remaining processing system cannot handle all of the stimulus input or all of the response output at the same time. Therefore, how to maintain attention should be worthy of further study and concern.

\section{Acknowledgements}

We would like to express my great gratitude to my supervisors who provided insight and expertise that greatly assisted this research. We also should thank the Faculty of Modern Languages and Communication, Universiti Putra Malaysia for the support provided during the research process.

\section{References}

Brandt, D. (2017). Understanding Memory in Advertising. Innovation. Retrieved from: http://www.nielsen.com/us/en/insights/journal-of-measurement/volume-1-issue-3/understandingmemory-in-advertising.html. [Accessed 2020, September 30]

Friedman, H. H., \& Friedman, L. (1979). Endorser Effectiveness by Product Type. Journal of Advertising Research.

García-Rapp, F. (2017). Popularity Markers on YouTube's Attention Economy: The Case of Bubzbeauty. Celebrity Studies, 8(2), 228-245.

Goldhaber, M. H. (1997). Attention Shoppers. Wired Magazine, 5, 12.

Hu, G. (2003). Effective Attention: The Way to E-commerce Success. Journal of Xiangtan University (Philosophy and Social Sciences), 4, 41-43. 
Jiang, Q. P. (2005). Meaning-Based Attention Economy-Version 2.0 of Attention Economy. China Internet Week, 20, 80-82.

Jiao, F. (2018). The Economy of Attention. Retrieved from: http://www.36odoc.com/content/14/0520/19/7430908_379421812.shtml. [Accessed 2020, September 1]

Jorgensen, D. L. (2015). Participant Observation. Emerging Trends in the Social and Behavioural Sciences: An Interdisciplinary, Searchable, and Linkable Resource, 1-15.

Kerrigan, S., \& McIntyre, P. (2010). The 'Creative Treatment of Actuality': Rationalizing and Reconceptualizing the Notion of Creativity for Documentary Practice. Journal of Media Practice, 11(2), 111130.

Lanham, R. A. (2006). The Economics of Attention: Style and Substance in the Age of Information. University of Chicago Press.

Law, J. (2011). Business: The Ultimate Resource (3rd ed.). London, UK: A\&C Black.

Marwick, A. E. (2013). Status Update: Celebrity, Publicity, and Branding in the Social Media Age. Yale University Press.

O'Mahony, S. \& Meenaghan, T. (1997). The Impact of Celebrity Endorsements on Consumers. Irish Marketing Review, 10(2), 15.

Opdenakker, R. (2006). Advantages and Disadvantages of Four Interview Techniques in Qualitative Research. In Forum Qualitative Sozialforschung/Forum: Qualitative Social Research, 7(4).

Ratcliffe, J. (2014). Identifying the Key Concepts of Marketing: Attention, Interest, Desire and Action. Journal of Aesthetic Nursing, 3(7), 358-359.

Singh, K. J. (2010). Features, Advantages and Disadvantages of Observation. MBA Official. Retrieved from: https://www.mbaofficial.com/mba-courses/research-methodology/features-advantages -and-disadvantages-of-observation. [Accessed 2020, September 3]

Spielman, H. M. (1981). The Celebrity Sell: Making it Work. Marketing Times, 28(6), 13-14.

Zulli, D. (2018). Capitalizing on the Look: Insights into the Glance, Attention Economy, and Instagram. Critical Studies in Media Communication, 35(2), 137-150.

\section{Figures}

Figure 2: Celebrity-based advertisement of M\&M's. Retrieved September, 7, 2020, from https://v.youku.com/v_show/id_XNzkyODA4NTAo.html?fromvsogou=1\&ctid=16be3949de72c4ed\&refer =pgy_operation.wulin.tl_oooo3189_1000_mymaia_19060400.

Figure 3: Content-based advertisement of M\&M's. Retrieved September, 7, 2020, from https://www.iqiyi.com/w_19ryiayylx.html?fromvsogou=1\&fv=bf562ffcıcd15119. 